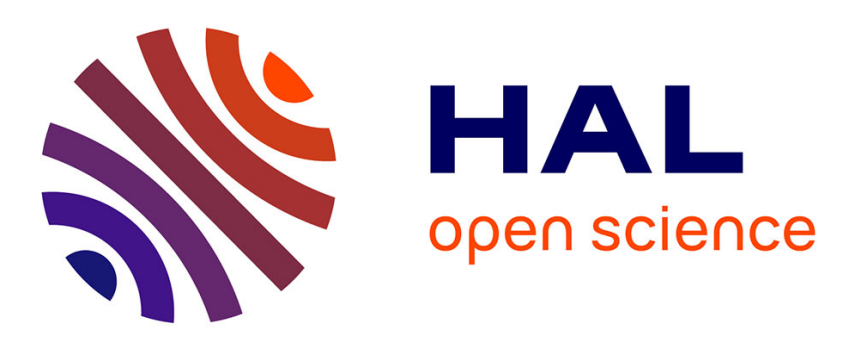

\title{
Effect of sodium to barium substitution on the space charge implementation in thermally poled glasses for nonlinear optical applications
}

\author{
Artem Malakho, Marc Dussauze, Evelyne Fargin, Olivier Bidault, Vincent \\ Rodriguez, Frédéric Adamietz, Bertrand Poumellec
}

\section{To cite this version:}

Artem Malakho, Marc Dussauze, Evelyne Fargin, Olivier Bidault, Vincent Rodriguez, et al.. Effect of sodium to barium substitution on the space charge implementation in thermally poled glasses for nonlinear optical applications. Journal of Solid State Chemistry, 2009, 182 (5), pp.1156-1163. 10.1016/j.jssc.2009.02.016 . hal-00381987

\section{HAL Id: hal-00381987 https://hal.science/hal-00381987}

Submitted on 12 Jul 2021

HAL is a multi-disciplinary open access archive for the deposit and dissemination of scientific research documents, whether they are published or not. The documents may come from teaching and research institutions in France or abroad, or from public or private research centers.
L'archive ouverte pluridisciplinaire HAL, est destinée au dépôt et à la diffusion de documents scientifiques de niveau recherche, publiés ou non, émanant des établissements d'enseignement et de recherche français ou étrangers, des laboratoires publics ou privés. 


\title{
Effect of sodium to barium substitution on the space charge implementation in thermally poled glasses for nonlinear optical applications
}

\author{
Artem Malakho ${ }^{\mathrm{a}}$, Marc Dussauze ${ }^{\mathrm{b}, \mathrm{e}, *}$, Evelyne Fargin $^{\mathrm{c}}$, Olivier Bidault $^{\mathrm{d}}$, Vincent Rodriguez ${ }^{\mathrm{e}}$, \\ Frederic Adamietz ${ }^{\mathrm{e}}$, Bertrand Poumellec ${ }^{\mathrm{f}}$

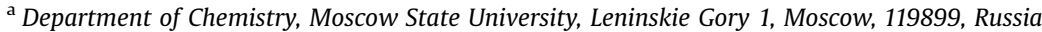 \\ ${ }^{\mathrm{b}}$ Theoretical and Physical Chemistry Institute, National Hellenic Research Foundation, 48 Vassileos Constantinou Avenue, 11635 Athens, Greece \\ ${ }^{c}$ Institut de Chimie de la Matière Condensée de Bordeaux-UPR 9048 CNRS Chateau Brivazac, Avenue du Dr. Schweitzer, 33608 Pessac Cedex, France \\ d Laboratoire de Physique du Solide, Université de Bourgogne, Boîte Postale 138, 21004 Dijon, France \\ e Institut des Sciences Moléculaires, UMR 5255 CNRS, Université Bordeaux 1351 cours de la Libération, 33405 Talence Cedex, France \\ ${ }^{\mathrm{f}}$ Institut de Chimie Moléculaire et Matériaux d'Orsay/Laboratoire de Physico-Chimie de l'Etat Solide, UMR 8182 CNRS-UPS Université de Paris Sud, \\ Bât. 414, 91405 Orsay Cedex, France
}

Keywords:

Thermal poling

Space charge

Second harmonic generation

Borophosphate glasses

Ionic conductivity

\begin{abstract}
A B S T R A C T
Thermally poled niobium borophosphate glasses in the system $0.55(0.95 \quad y) \mathrm{NaPO}_{3}+y / 2 \mathrm{Ba}\left(\mathrm{PO}_{3}\right)_{2}+0.05$ $\left.\mathrm{Na}_{2} \mathrm{~B}_{4} \mathrm{O}_{7}\right)+0.45 \mathrm{Nb}_{2} \mathrm{O}_{5}$ were investigated for second order optical nonlinear (SON) properties. Bulk glasses were studied by Raman spectroscopy, thermal analysis, optical and dielectric measurements. The sodium to barium substitution does not lead to significant changes in optical properties, crystallization of glasses and coordination environment of polarizable niobium atoms. However, the ionic conductivity decreases drastically with the increase of barium concentration. Secondary ion mass spectroscopy has been used to determine the element distribution in the anode layer of the thermally poled glasses. The second order optical susceptibilities gradually decrease from $\chi^{(2)}=2.8 \mathrm{pm} / \mathrm{V}$ to zero with the increase of barium content. Using a simple electrical model, variations of nonlinear optical responses have been correlated with dielectric characteristics.
\end{abstract}

\section{Introduction}

Second order optical nonlinearity (SON) in glasses induced by thermal poling was first discovered by Myers et al. for silica [1,2]. It was shown that the induced quadratic optical nonlinearity in thermally poled glasses is mainly due to a space charge/an internal electric field created at the anode surface by the migration of cations. The interaction of the internal electric field, $E_{\mathrm{dc}}$, together with the third order optical nonlinearity, $\chi^{(3)}$, allows the creation of an efficient second order optical suscept ibility, $\chi^{(2)}[3]$

$\chi^{(2)}(2 \omega ; \omega, \omega)=3 \chi^{(3)}(2 \omega ; \omega, \omega, 0) \cdot E_{\mathrm{int}}$

Thus, to optimize the $\chi^{(2)}$ efficiency in a poled glass, the choice of a new composition can be led on the basis of $\chi^{(3)}$ values by

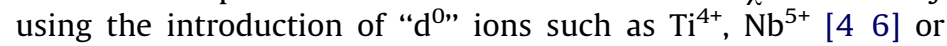
heavy cations having an electronic configuration with $\mathrm{ns}^{2}$ lone pairs $\left(\mathrm{Te}^{4+}, \mathrm{Bi}^{3+}, \mathrm{Tl}^{+}\right)[7]$. In addition, a glass composition might be

\footnotetext{
* Corresponding author at: Institut des Sciences Moléculaires, UMR 5255 CNRS, Université Bordeaux 1351 cours de la Libération, 33405 Talence Cedex, France. E-mail address: m.dussauze@ism.u-bordeaux1.fr (M. Dussauze).
}

chosen with the aim to optimize the value of the imbedded electric field, $E_{\text {int }}$. In that sense, recent studies have shown that glasses with large concentration of charge carriers can exhibit significant quadratic optical nonlinearity after thermal poling [8 10]. These promising results point out the importance of concentration and mobility of cations on the efficiency of a thermal poling treatment. For instance, in the particular system $(1 \quad x)\left(0.95 \mathrm{NaPO}_{3}+0.05 \mathrm{Na}_{2} \mathrm{~B}_{4} \mathrm{O}_{7}\right)+x \mathrm{Nb}_{2} \mathrm{O}_{5}$, both second $\left(\chi^{(2)}\right)$ and third $\left(\chi^{(3)}\right)$ order optical susceptibilities increase significantly with the niobium content $[6,10,11]$. At the opposite, in the system $\left(\begin{array}{ll}1 & x\end{array}\right)\left(0.9 \mathrm{Ca}\left(\mathrm{PO}_{3}\right)_{2}+0.1 \quad \mathrm{CaB}_{4} \mathrm{O}_{7}\right) \quad x \mathrm{Nb}_{2} \mathrm{O}_{5}, x=050[12,13], \chi^{(3)}$ values increase with the niobium oxide concentration and the induced $\chi^{(2)}$ remain quite constant in the range $0.420 .5 \mathrm{pm} / \mathrm{V}$. For these two particular systems, i.e. the same glass matrix modified either by sodium or calcium, one has observed either the presence or the absence of correlation between $\chi^{(2)}$ and $\chi^{(3)}$. According to Eq. (1), such differences clearly indicate that the nature of mobile charge carriers is a key point to optimize the internal electric field induced by poling and thus to optimize the SON properties of poled glasses.

In this work, borophosphate glasses in the system 0.55 $\left((0.95 y) \mathrm{NaPO}_{3}+y / 2 \mathrm{Ba}\left(\mathrm{PO}_{3}\right)_{2}+0.05 \mathrm{Na}_{2} \mathrm{~B}_{4} \mathrm{O}_{7}\right)+0.45 \mathrm{Nb}_{2} \mathrm{O}_{5} \quad(y=0$, $0.1,0.3,0.5,0.8)$ were studied in order to determine the influence 
of ionic conductivity on thermal poling conditions and quadratic optical nonlinearity values. Piecemeal replacement of sodium on barium is expected to change the ionic conductivity keeping the niobium content relatively constant. A tentative correlation between the induced $\chi^{(2)}$ responses and the dielectric character istics of poled glasses will be presented.

\section{Experimental}

\subsection{Samples preparation and characterization}

Transparent amorphous glasses of compositions 0.55((0.95 $y)$ $\left.\mathrm{NaPO}_{3}+y / 2 \mathrm{Ba}\left(\mathrm{PO}_{3}\right)_{2}+0.05 \mathrm{Na}_{2} \mathrm{~B}_{4} \mathrm{O}_{7}\right)+0.45 \mathrm{Nb}_{2} \mathrm{O}_{5}$ with $y=0,0.1,0.3$, $0.5,0.8$ (hereafter marked as NBP45 NBP45Ba10, NBP45Ba30, NBP45Ba50 and NBP45Ba80, respectively) were prepared from commercial reagent grade powders of $\mathrm{NaPO}_{3}$ (Merck, 99.9\%), $\mathrm{BaCO}_{3}$ (Aldrich 99.98\%), $\mathrm{Na}_{2} \mathrm{~B}_{4} \mathrm{O}_{7}$ (Alfa Aesar, 99.5\%) and $\mathrm{Nb}_{2} \mathrm{O}_{5}$ (Cerac, 99.99\%). To achieve a total replacement of sodium by barium, the glass $0.55\left(0.475 \mathrm{Ba}\left(\mathrm{PO}_{3}\right)_{2}+0.05 \mathrm{BaB}_{4} \mathrm{O}_{7}\right)+0.45 \mathrm{Nb}_{2} \mathrm{O}_{5}$ (hereafter marked as NBP45Ba100) was also prepared. As mentioned above, compositions of prepared glasses were chosen to provide sequential replacement of two $\mathrm{Na}^{+}$by one $\mathrm{Ba}^{2+}$ keeping constant the relative proportions of other atoms.

Stoichiometric mixtures of starting materials were melted in platinum crucible at $1673 \mathrm{~K}$ for $30 \mathrm{~min}$ in air. The melt was poured on a brass plate and quenched by sandwiching with another brass plate to obtain $1 \mathrm{~mm}$ thick glasses. Quenched glasses were annealed at $873 \mathrm{~K}$ for $24 \mathrm{~h}$ in order to diminish internal stresses. Annealing of barium containing glasses was done in an oxygen atmosphere to avoid a blue coloration due to the partial reduction of $\mathrm{Nb}^{5+}$ to $\mathrm{Nb}^{4+}$. All glasses were homogeneous and free of crystals. Samples were cut and polished on both sides for optical characterization.

Thermal analyses were performed on the DSC (differential scanning calorimetry) apparatus (SSC $5400 \mathrm{H}$ Seiko instruments) in the $50950{ }^{\circ} \mathrm{C}$ temperature range with a heating rate of $10 \mathrm{~K} / \mathrm{min}$. Platinum was used as reference sample. The glass transition temperatures $\left(T_{\mathrm{g}}\right)$ and crystallization onset tempera tures $\left(T_{\mathrm{c}}\right)$ were determined from tangent intersection of the DSC curves. The measured values of $T_{\mathrm{g}}$ and $T_{\mathrm{c}}$ were reproducible with an accuracy of $\pm 5 \mathrm{~K}$. Density measurements were performed using the Archimede method with diethylorthophtalate as immersion liquid.

$X$ ray diffraction (XRD) patterns of initial and heat treated samples were collected on Philips Xpert powder diffractometer ( $\mathrm{CuK} \alpha$ radiation, $\theta \quad \theta$ geometry, reflection mode) at room tem perature. The Raman spectra were recorded with a Labram confocal micro Raman instrument (typical resolution of $3 \mathrm{~cm}^{1}$ ), in the backscattering geometry at room temperature. The spectro photometer includes a holographic Notch filter for Rayleigh rejection, a microscope equipped with $100 \times$ objectives, and a CCD detector. The $514.5 \mathrm{~nm}$ emission line of an argon ion laser was used for excitation.

\subsection{Dielectric properties}

Prior to the measurements, the faces of the polished glass plates were electroded with platinum using rf magnetron sputtering. Gold or silver was avoided because a diffusion takes place on heating the sample above $200^{\circ} \mathrm{C}$. The dielectric response was measured under a weak ac field $(0.1 \mathrm{kV} / \mathrm{cm})$ using an HP 4194 impedance analyzer covering a frequency range from $100 \mathrm{~Hz}$ to $10 \mathrm{MHz}$. The temperature was controlled using a chromel alumel thermocouple directly in contact with the sample; it could be monitored between 300 and $800 \mathrm{~K}$ with an accuracy better than $0.5 \mathrm{~K}$.

\subsection{Secondary ion mass spectrometry (SIMS)}

SIMS measurements were performed on CAMECA IMS 4F spectrometer. Excitation of secondary ion emission was made by a focused primary ion beam of $\mathrm{Cs}^{+}$at $14.5 \mathrm{keV}$ under an incident angle of $26^{\circ}$ (for registration of negative secondary ions, sample was biased to $4.39 \mathrm{kV}$ ) and a beam of $\mathrm{O}^{2+}$ at $5.5 \mathrm{keV}$ under an incident angle of $42^{\circ}$ (for registration of positive secondary ions, sample is biased to $+4.38 \mathrm{kV}$ ). To avoid charging, samples were covered by thin layer of gold $(\sim 30 \mathrm{~nm})$. In order to diminish the contribution of molecular ions, registered ions were separated on energy with $150 \mathrm{eV}$ offset. Distributions of elements in poled and nonpoled samples were analyzed by etching of the surface with ion beam. An area of $0.125 \times 0.125 \mathrm{~mm}^{2}$ was scanned by ion beam and during this process the signals of selected elements were recorded from an area of $30 \mu \mathrm{m}$ in diameter at the center of the crater created by the ion bombardment, as function of time. Etching rate was calculated from the depth of the crater measured by profilometer Tencor.

\subsection{Optical measurements and thermal poling}

Optical transmission spectra were recorded at room tempera ture using double beams spectrophotometer CARY (UV Vis NIR) in the wavelength range $2003000 \mathrm{~nm}$. The polished samples with $500 \mu \mathrm{m}$ thickness were used for measurements.

Thermal poling experiments were performed using the following procedure: $500 \mu \mathrm{m}$ thick samples were sandwiched between polished silicon wafer at the anode and thin borosilicate glass plate at the cathode, then pressed on both sides and heated (temperatures are noted in Table 3 ). The poling voltage 1.5 or $2 \mathrm{kV}$ was applied for $30 \mathrm{~min}$. Increase of poling voltage led to dielectric breakdown and mechanical destruction of the sample. Samples were cooled down before the external voltage was removed.

Measurements of refractive indices and SHG responses were performed as described earlier [14]. The source was a Q switched $\mathrm{Nd} /$ YAG laser operating at wavelength $1064 \mathrm{~nm}$. The pulse width and the repetition rate of output pulses from the laser were $15 \mathrm{~ns}$ and $30 \mathrm{~Hz}$, respectively. The polarized source beam was split into two branches by a beam splitter. One branch recorded the fundamental intensity with a Ge photodiode, the other which passed through a polarizer to adjust its polarization, was focused on the sample with a spot of $100 \mu \mathrm{m}$ in diameter. The $2 \omega$ transmitted signals were detected by a first photomultiplier and averaged over 50 pulses. The pulse energies at the sample were no more than $150 \mu \mathrm{J}$ for the infrared beam. The calibration of the SHG intensities is obtained using a quartz $\mathrm{z}$ cut taking $d_{11}=0.3 \mathrm{pm} / \mathrm{V}$ at $1064 \mathrm{~nm}$ as reference [15]. This versatile experimental setup allows linear refractive index to be estimated at $\omega$ or $2 \omega$ with a second photomultiplier by collecting the corresponding $2 \Theta$ reflected wave around the Brewster angle over the $1080^{\circ} \Theta$ range. $\mathrm{A} \mathrm{LiNbO}_{3}$ crystal in phase matching condition was used as a $532 \mathrm{~nm}$ source. The Maker fringes were analyzed using a general ellipsometrical analysis for planar multilayered media [14]. Maker fringes signals, with pp and sp polarization configurations, where $\mathrm{pp}$ (sp) means p polarized (s polarized) incident pump beam and $\mathrm{p}$ polarized transmitted second harmonic beam, were recorded for the studied samples. The determined values of the linear refractive indices were used in further simulations to allow the estimation of the nonlinear zone thickness with good accuracy. The step like profile has been used to approximate the thickness and SON efficiency in the nonlinear layer computations. The only 
nonlinear coefficients which are nonzero are $d_{33}=1 / 2 \chi_{\mathrm{zzz}}^{(2)}$ and $d_{31}=d_{33} / 3$ in accordance with the polar symmetry generated by poling treatment.

\section{Results}

Transparent yellow homogeneous glasses were obtained for all compositions under study. Density of the samples increases with barium content while the volume concentration of niobium remain practically unchanged $\sim 18.5 \times 10^{3} \mathrm{~mol} / \mathrm{cm}^{3}\left(11.1 \times 10^{21}\right.$ atoms $/ \mathrm{cm}^{3}$ ). Optical transmission spectra for glasses NBP45Ba10, NBP45Ba50, NBP45Ba100 are shown in Fig. 1, refractive indices and positions of absorption edges are presented in Table 1. Replacement of sodium by barium does not change significantly absorption spectra and refractive indices. Absorption lines which may correspond to $\mathrm{Nb}^{4+}$ are not visible on transmission spectra.

Raman spectra of glasses in the spectral range $4001600 \mathrm{~cm}^{1}$ are depicted in Fig. 2. All spectra contain a large broad band composed of three main components at 670,800 and $900 \mathrm{~cm}{ }^{1}$. The higher frequency shoulder at $900 \mathrm{~cm}{ }^{1}$ is attributed to $\mathrm{NbO}_{6}$ octahedra with nonbridging oxygen atoms, $\mathrm{Nb} \mathrm{O} \ldots \mathrm{Na}^{+}$, while modes associated with bridging bonds of the phosphoniobate network are expected in the $500850 \mathrm{~cm}{ }^{1}$ range. These include $\mathrm{NbO}_{6}$ octahedra bridging with niobium and phosphorus centers $\left(750850 \mathrm{~cm}^{1}\right.$ ) and $\mathrm{Nb} \mathrm{O} \mathrm{Nb}$ bonds in a 3D niobate network $\left(600750 \mathrm{~cm}^{1}\right)[6,11,16]$. Less intensive bands at 1020 and

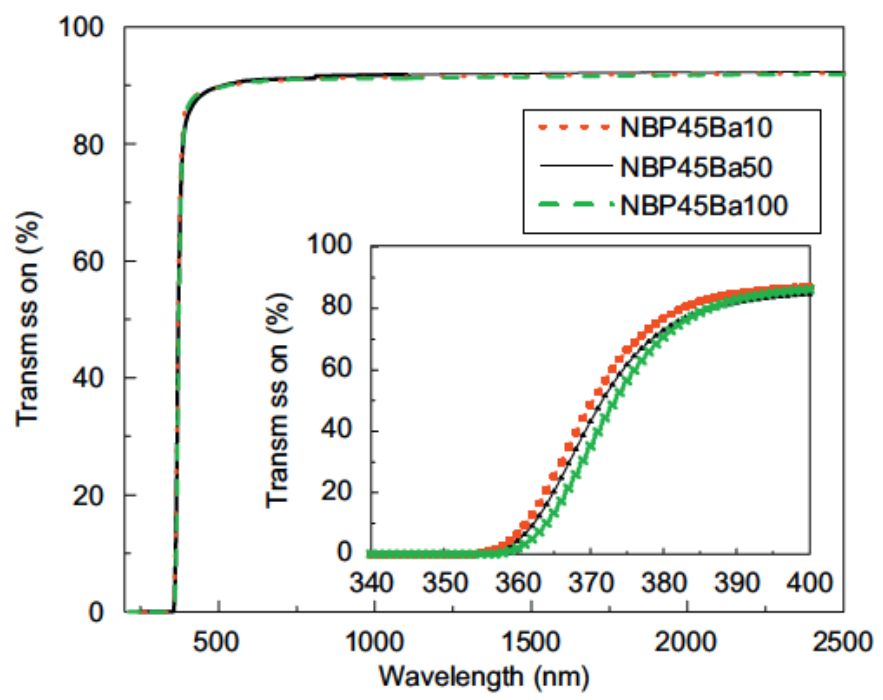

Fig. 1. Optical transmission spectra of glasses NBP45Ba10, NBP45Ba50, NBP45Ba100. Details of the spectra in wavelength range $340-400 \mathrm{~nm}$ are shown on inset.
$1140 \mathrm{~cm}{ }^{1}$ correspond to vibrations of phosphate groups [17,18]. One can observe that positions and intensities of bands do not change significantly with replacement of sodium by barium. Only slight broadening of all Raman bands is observed with increase of barium concentration. This observation might be explained as a slight modification of the glass framework with a wider distribu tion of lengths for $\mathrm{Nb} \mathrm{O}$ and $\mathrm{P} \mathrm{O}$ bonds. In addition, the similarity between Raman spectra upon cations substitutions may indicate that the sodium to barium substitution does not influence to a large extend the niobate network.

Thermal analysis of NBP45Ba10 Ba100 bulk glasses shows an increase of glass stability (difference of glass transition and crystallization temperature $\Delta T=T_{\mathrm{c} 1} T_{\mathrm{g}}$ ) with barium concentra tion (Fig. 3). Barium is less mobile than sodium and forms stronger coordination environment. As a result, higher energy is necessary for atom displacements and migration that take place during nucleation and growth of crystallites.

Crystalline phases were determined by $\mathrm{X}$ ray powder diffrac tion analysis of crystallized glass samples. Crystallization was performed by continuous heating of samples with a rate of $10 \mathrm{~K} / \mathrm{min}$ till the maximum temperature of crystallization peak and then quenched in air. Temperatures of endothermic and exothermic effects corresponding, respectively, to glass transitions $\left(T_{\mathrm{g}}\right)$, and beginning of crystallization processes $\left(T_{\mathrm{c}}\right)$, as well as results of phase analysis of crystallized glasses are collected in Table 2.

First crystallization maximum corresponds to the phase $\mathrm{Na}_{1.1} \mathrm{Nb}_{2.98} \mathrm{O}_{8}$ for all sodium containing glasses. Crystallization

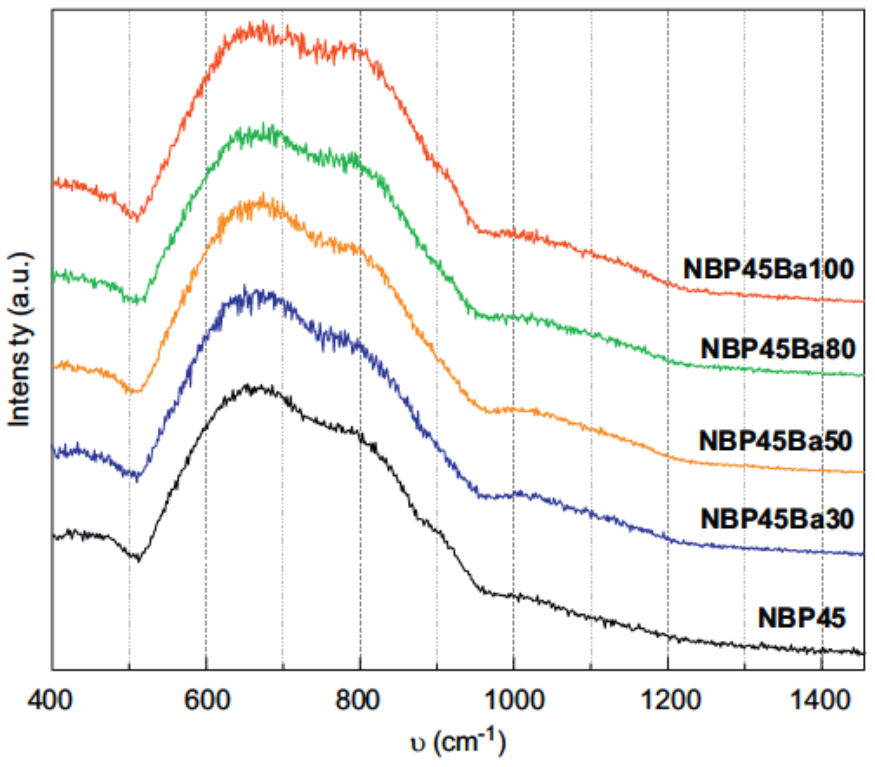

Fig. 2. Raman spectra for glasses NBP45, NBP45Ba30-Ba100.

Table 1

Refractive indices and absorption edges for glasses NBP45Ba with various concentration of barium.

\begin{tabular}{|c|c|c|c|c|}
\hline \multirow[t]{2}{*}{ Sample } & \multirow[t]{2}{*}{ Density $\left(\mathrm{g} / \mathrm{cm}^{3}\right) \pm 0.01$} & \multicolumn{2}{|c|}{ Refractive indices \pm 0.02} & \multirow[t]{2}{*}{ Absorption edge $(\mathrm{nm}) \pm 2$} \\
\hline & & $\lambda \quad 1064(\mathrm{~nm})$ & $\lambda \quad 532(\mathrm{~nm})$ & \\
\hline NBP45 & 3.66 & 1.91 & 1.99 & 360 \\
\hline NBP45Ba10 & 3.69 & 1.93 & 1.98 & 355 \\
\hline NBP45Ba30 & 3.79 & Not quantified & & \\
\hline NBP45Ba50 & 3.88 & 1.94 & 2.03 & 358 \\
\hline NBP45Ba80 & 4.06 & Not quantified & & \\
\hline NBP45Ba100 & 4.20 & 1.93 & 2.02 & 363 \\
\hline
\end{tabular}




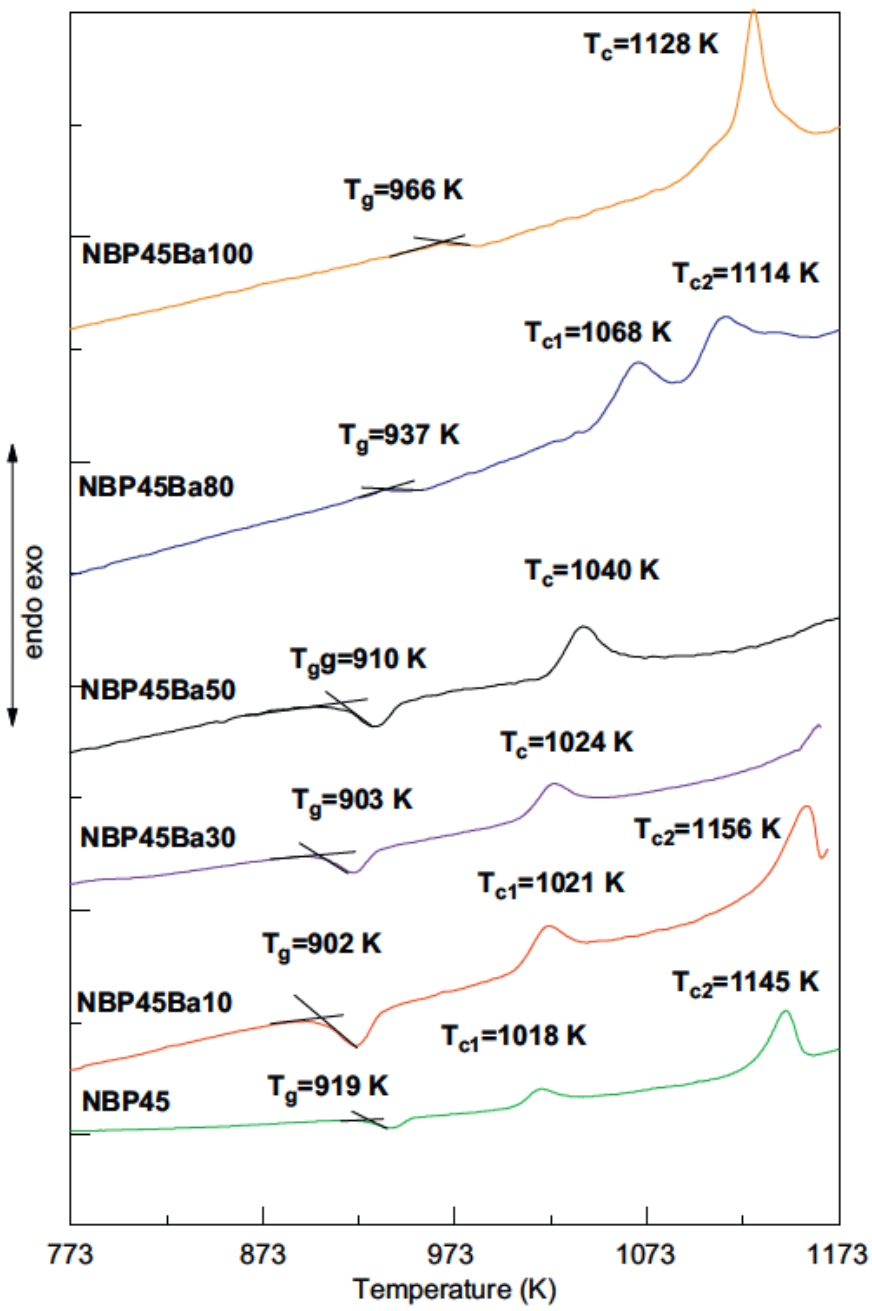

Fig. 3. DTA curves for glasses NBP45, NBP45Ba10-Ba100.

Table 2

Density, glass transition ( $\left.T_{\mathrm{g}}\right)$, crystallization $\left(T_{\mathrm{c}}\right)$ temperatures for glasses NBP45Ba10-Ba100, and crystal phases which correspond to crystallization effects.

\begin{tabular}{lllll}
\hline \multirow{2}{*}{ Sample } & \multicolumn{2}{l}{ Temperature $(\mathrm{K})$} & \multicolumn{2}{l}{ Crystallizing phases } \\
\cline { 2 - 4 } & $T_{\mathrm{g}}$ & $T_{\mathrm{c} 1}$ & $T_{\mathrm{c} 2}$ & \\
\hline NBP45 & 919 & 1018 & 1145 & $\mathrm{Na}_{1.1} \mathrm{Nb}_{2.98} \mathrm{O}_{8}\left(T_{\mathrm{c} 1}\right)+\mathrm{Na}_{4} \mathrm{Nb}_{8} \mathrm{P}_{4} \mathrm{O}_{32}\left(T_{\mathrm{c} 2}\right)$ \\
NBP45Ba10 & 902 & 1021 & 1156 & $\mathrm{Na}_{1.1} \mathrm{Nb}_{2.98} \mathrm{O}_{8}\left(T_{\mathrm{c} 1}\right)+\mathrm{Na}_{4} \mathrm{Nb}_{8} \mathrm{P}_{4} \mathrm{O}_{32}\left(T_{\mathrm{c} 2}\right)$ \\
NBP45Ba30 & 903 & 1024 & - & $\mathrm{Na}_{1.1} \mathrm{Nb}_{2.98} \mathrm{O}_{8}\left(T_{\mathrm{c} 1}\right)$ \\
NBP45Ba50 & 910 & 1040 & - & $\mathrm{Na}_{1.1} \mathrm{Nb}_{2.98} \mathrm{O}_{8}\left(T_{\mathrm{c} 1}\right)$ \\
NBP45Ba80 & 937 & 1068 & 1114 & $\mathrm{Na}_{1.1} \mathrm{Nb}_{2.98} \mathrm{O}_{8}\left(T_{\mathrm{c} 1}\right)+\mathrm{BaNb}_{2} \mathrm{P}_{2} \mathrm{O}_{11}\left(T_{\mathrm{c} 2}\right)$ \\
NBP45Ba100 & 966 & - & 1128 & $\mathrm{BaNb}_{2} \mathrm{P}_{2} \mathrm{O}_{11}\left(T_{\mathrm{c} 2}\right)$ \\
\hline
\end{tabular}

behaviors of sodium niobium borophosphate glasses and structural particularities of $\mathrm{Na}_{1.1} \mathrm{Nb}_{2.98} \mathrm{O}_{8}$ phase were studied earlier [19]. For samples NBP45, NBP45Ba10 the second peak $(\sim 1150 \mathrm{~K})$ has been attributed to crystallization of $\mathrm{Na}_{4} \mathrm{Nb}_{8} \mathrm{P}_{4} \mathrm{O}_{32}$ phase (PDF $2 \# 440026$, sp. gr. $P 2_{1}, a=6.6287 \AA$, $b=5.3563 \AA$, $c=17.947 \AA, \beta=90.0^{\circ}$ ) [20]. At higher concentration of barium the $\mathrm{BaNb}_{2} \mathrm{P}_{2} \mathrm{O}_{11}$ phase (PDF $2 \# 400107$ sp. gr. $R 3 c, a=5.072 \AA$, $c=59.1 \AA$ ) [21] has been observed for NBP45Ba80 and NBP45Ba100 samples crystallized at $\sim 1120 \mathrm{~K}$.

The conductivity spectra $\sigma(\omega)$ of as prepared glasses were recorded in the temperature range $400800 \mathrm{~K}$. The observed conductivity spectra of NBP45Ba30 and NBP45Ba80 glasses reported in Fig. 4 are typical of an ionic conductive glass. At low frequencies, the conductivity is independent of the frequency and corresponds to the dc conductivity $\left(\sigma_{\mathrm{dc}}\right)$ whereas one notes dispersion at higher frequencies. Within this standard frequency window and this temperature range, the frequency response of the (real part of the) conductivity is currently described by a power law dependence:

$\sigma(\omega)=\sigma_{\mathrm{dc}}+A \omega^{n}$

It decomposes as the sum of a constant dc conductivity and a fractional frequency dependence $(n<1)$ with a pre factor A. All the spectra could be fitted using this simple model (Eq. (2)). As shown in Fig. 5, $\sigma_{\mathrm{dc}}$ of glasses NBP45, NBP45Ba30 and NBP45Ba80 present an Arrhenius behavior. Values of conductivity decrease by some orders of magnitude while the activation energies $\left(E_{\mathrm{a}}\right)$ increase upon cations substitutions. Such an effect may be explained as a blocking of sodium hopping and migration paths due to the presence of the less mobile barium atoms.

Because of the high difference in conductivity, it is not experimentally possible to polarize all the glasses under the same charge. Thus, in a first step the same thermal poling parameters ( $1503 \mathrm{~K}, V=1.52 \mathrm{kV}, t=30 \mathrm{~min})$, known as optimized for the NBP45 glass [10], were used for all the compositions. Efficient second harmonic signal were collected for poled glasses NBP45, NBP45Ba10 Ba30 Ba50. At the inverse, no SHG signal was detected for samples NBP45Ba80 Ba100. Then in a second step, for high concentration of Barium tentative to increase the poling voltage leads to dielectric breakdown and mechanical destruction of samples. Poling at $573 \mathrm{~K}, 2 \mathrm{kV}, t=30 \mathrm{~min}$ do not give any SHG signal too. Further increasing of poling temperature leads to strong sticking of silicon electrode to the glass surface and it was not possible to separate glass and electrode and to keep poled surface undamaged.

Upon cations substitution, the Maker fringes analyses (see Table 3, Fig. 6.) have shown a gradual decrease of both the induced $\chi_{\mathrm{zzz}}^{(2)}$ coefficient and the NLO layer thickness, from $2.8 \mathrm{pm} / \mathrm{V}$ and $4.3 \mu \mathrm{m}$ to $0.8 \mathrm{pm} / \mathrm{V}$ and $1.9 \mu \mathrm{m}$ for the samples NBP45 and NBP45Ba50, respectively.

Ions displacements under electric field have been character ized by SIMS. As prepared and thermally poled samples of NBP45Ba10 glass were studied. Measurements were performed in SIMS dynamic regime. Etching of surface with speed $45 \AA / s$ was performed to study distribution of elements on depth of poled and nonpoled zone. Experiments with registration of both positive and negative secondary ions permit to analyze elements contained in glasses under study. SIMS analysis is a qualitative technique and precise values of atomic concentration can not be extracted from data without special calibrations.

If we consider that the profile in the first $50 \mathrm{~nm}$ is due to charge distribution stabilization in the SIMS method, homoge neous distributions of all elements (excepted $\mathrm{H}$ and $\mathrm{C}$ ) were observed for nonpoled glass (Fig. 7). On the contrary, some pollution of organic substances was observed on extreme surface of samples (50 $100 \mathrm{~nm}$ ) leading to $\mathrm{H}$ and $\mathrm{C}$ profiles. At the anode side of thermally poled glass more complicated distributions of elements take place (Fig. 8). In the thermally poled NBP45Ba10 glass, pollutions from organics are observed on the $\sim 120 \mathrm{~nm}$ surface layer of poled zone. A complete depletion of sodium was pointed out in a layer of $\sim 3 \mu \mathrm{m}$ thickness under the anode surface. SIMS analysis is an extremely sensitive technique and traces of sodium are surprisingly absent in the depleted region. The border of the depleted region is rather sharp and does not exhibit a clear diffusion profile. Injection of traces of sodium is observed on the profile of positively charged ions. Injected sodium is distributed in a layer of $0.5 \mu \mathrm{m}$ thick. The concentration of 

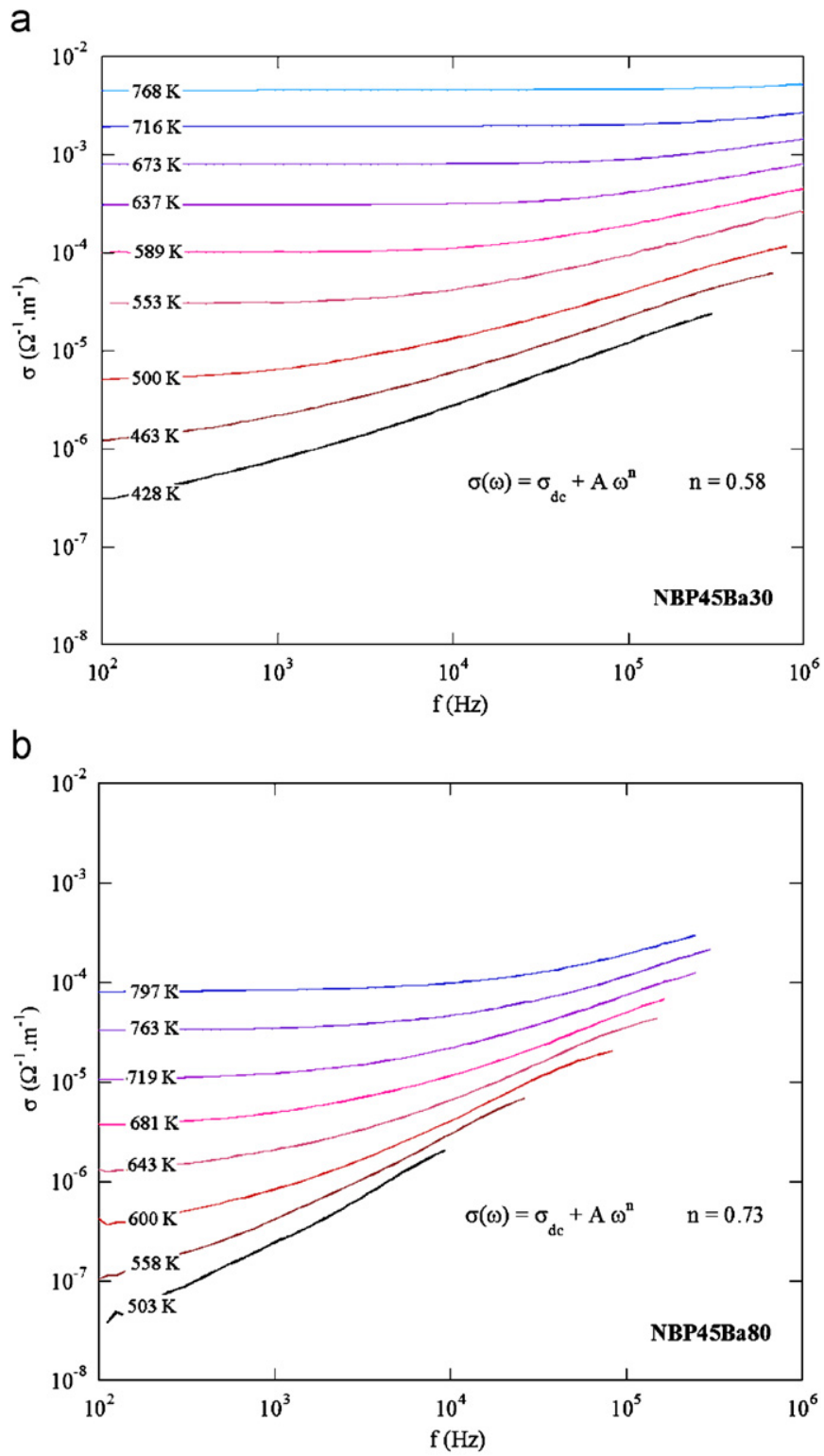

Fig. 4. Conductivity spectra $\sigma(\omega)$ obtained for NBP45Ba30 (a) and NBP45Ba80 (b) glasses at different temperatures.

sodium is maximal on the surface and then decreases gradually to zero. Maximal concentration of sodium in this layer is two orders of magnitude lower than in the bulk glass. This injection layer could not be clearly seen on the profile of negatively charged ions because this type of analysis is less sensitive to sodium ions. Small decrease of the barium concentration is observed in a layer of $\sim 0.75 \mu \mathrm{m}$ thick. Ettori et al. [22] have studied the migration of calcium and magnesium ions by "corona" poling of borosilicate glasses. A "pile up" effect was observed for these mobile ions with an accumulation behind the sodium depletion front.

A remarkable result is the shape of hydrogen profile in the poled zone. Hydrogen is already present in the as prepared NBP45Ba10 glasses before thermal poling. In contrast with results presented for thermally poled silica glasses [23,24], no injection of hydrogen is observed. Here, hydrogen ions migrate together with sodium ions during thermal poling and accumulate after the sodium depletion front. The concentration of remaining hydrogen in the depleted region is two times less than that in the bulk glass.

\section{Discussion}

If one refers to Eq. (1), $\chi^{(2)}$, variations have to be discussed on the basis of the respective influence of $\chi^{(3)}$ and $E_{\mathrm{dc}}$. Structural characterization and crystallization studies can provide indication regarding the third order NLO properties. In glasses containing a large proportion of niobium oxide, the $\chi^{(3)}$ response has been related to the formation of a 3D corner sharing arrangement of $\mathrm{NbO}_{6}$ octahedra in a tungsten bronze like structure arrangement $[6,11,16,25,26]$. Notably, Lipovskii et al. have clearly correlated the intensity of the Raman mode linked to $\mathrm{Nb} \mathrm{O} \mathrm{Nb}$ bridges in a 3D network (pointing at $650 \mathrm{~cm}^{1}$ in Fig. 2) with the electro optical Kerr coefficient [16]. In the present study, the sodium to barium substitution does not induce important modification of the Raman spectra. For all the compositions, the main contribution remains the vibrational mode due to $\mathrm{Nb} \mathrm{O} \mathrm{Nb}$ bridges in a 3D network at $650 \mathrm{~cm}{ }^{1}$. In addition, the crystallization studies show also the formation of the $\mathrm{Na}_{1.1} \mathrm{Nb}_{2.98} \mathrm{O}_{8}$ phase for all the compositions containing sodium (i.e. from NBP45 to NBP45Ba80). These 


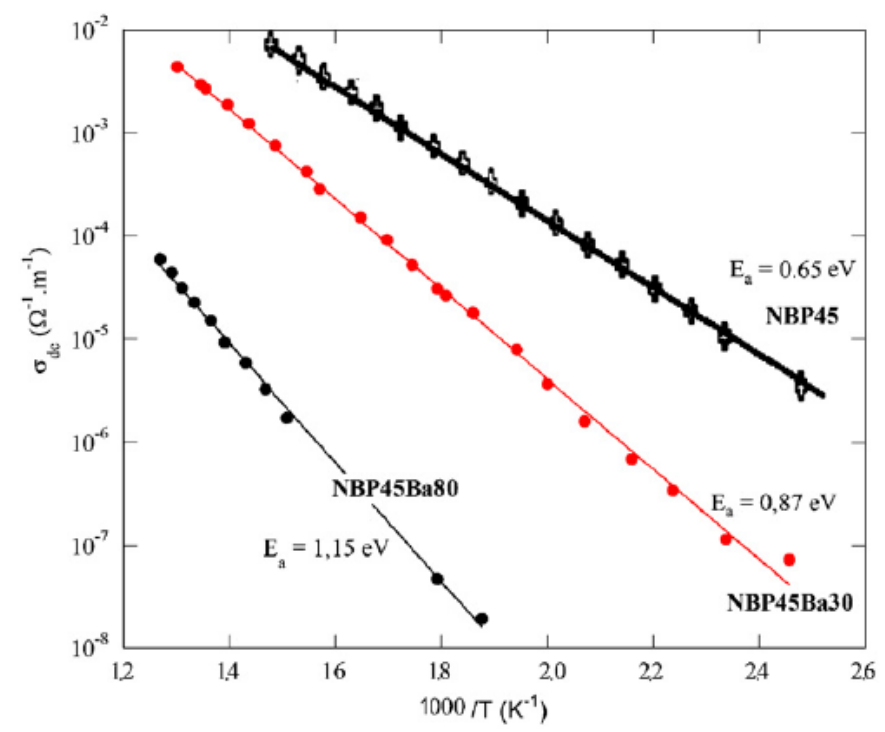

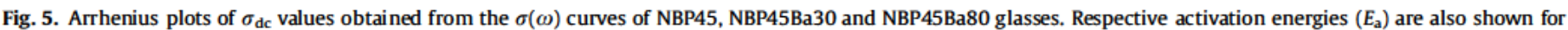
comparison purpose.

Table 3

Conditions of thermal poling, values of second order optical nonlinearity $\chi^{(2)}$ and thickness of nonlinear layer for glasses NBP45, NBP45Ba10-Ba100.

\begin{tabular}{|c|c|c|c|c|}
\hline \multirow{2}{*}{$\begin{array}{l}\text { Sample } \\
\text { NBP45 }\end{array}$} & \multicolumn{2}{|c|}{ Conditions of thermal polin } & \multirow{2}{*}{$\frac{\chi_{22 z 2}^{(2)}(\mathrm{pm} / \mathrm{V})}{2.8(2)}$} & \multirow{2}{*}{$\frac{\text { Layer thickness } L_{\mathrm{nl}}(\mu \mathrm{m}) \pm 0.2}{4.3}$} \\
\hline & $503 \mathrm{~K}, \mathrm{~V}$ & $1.5 \mathrm{kV}, t$ & & \\
\hline NBP45Ba10 & $T \quad 503 \mathrm{~K}, V$ & $1.5 \mathrm{kV}, t \quad 30 \mathrm{~min}$ & $2.5(2)$ & 4.4 \\
\hline NBP45Ba30 & $503 \mathrm{~K}, \mathrm{~V}$ & $2 \mathrm{kV}, t \quad 30 \mathrm{~min}$ & $2.0(2)$ & 3.7 \\
\hline NBP45Ba50 & $T \quad 503 \mathrm{~K}, V$ & $2 \mathrm{kV}, t \quad 30 \mathrm{~min}$ & $0.8(4)$ & 1.9 \\
\hline \multirow[t]{2}{*}{ NBP45Ba80 } & $T \quad 503 \mathrm{~K}, \mathrm{~V}$ & $30 \mathrm{~min}$ & \multirow[t]{2}{*}{ No detectable SHG signal } & \\
\hline & $T \quad 573 \mathrm{~K}, V$ & $2 \mathrm{kV}, t \quad 30 \mathrm{~min}$ & & \\
\hline \multirow[t]{2}{*}{ NBP45Ba100. } & $T \quad 503 \mathrm{~K}, V$ & $2 \mathrm{kV}, t \quad 30 \mathrm{~min}$ & \multirow[t]{2}{*}{ No detectable SHG signal } & \\
\hline & $T \quad 573 \mathrm{~K}, V$ & $2 \mathrm{kV}, \mathrm{t} \quad 30 \mathrm{~min}$ & & \\
\hline
\end{tabular}

observations let us estimate that the local environment of highly polarizable niobium octahedra does not change significantly upon cations substitutions. Thus, we do not expect large variations of the $\chi^{(3)}$ response within this compositional range. As drastic differences were observed in the $\chi^{(2)}$ values induced by poling, one should conclude that the internal electric field implementa tion during the poling treatment is highly dependant of the glass composition.

At this point, one has to consider the electric charge balance after poling. If we exclude an electric break down in the sample, the sodium depletion observed in the poled region corresponds to an enormous electric charge that has to be compensated. A first process insuring this compensation is charge injection. Clearly, positive charge injections could not be considered as the main mechanism of charge compensation as only hydrogen and carbon injection are detected by SIMS and their concentration are too low. Conductivity by negative charges most likely oxygen ions should be considered rather to explain the compensation of sodium departure. It means an ejection of oxygen from the glass to the anode which is not blocking for oxygen ( $\mathrm{Si}$ electrode). Unfortunately, the oxygen variation expected (i.e. 6.6\%) is not large enough to be detected clearly by SIMS in our conditions. As a matter of fact, a similar conclusion was made previously on the base of infrared spectroscopy [26] and we have observed a blue luminescence at the anode that is known to correspond to the oxidation of silicon [27]. However, one has to notice that for now we do not know in which electronic configuration oxygen is moving to permit the anionic conduction.

A model has been developed by Carlson to explain the formation of the nonlinear optical layer during thermal poling in sodium borosilicate glasses [28]. According to this model a first layer negatively charged called "dissociated" layer is supposed to appear due to charge dissociation. This layer screens the external electric field. Its thickness and the electric field at this location can be calculated from the Poisson formula. In a second stage, the electric field in this "dissociated" layer is supposed to be strong enough to initiate conductivity by negative charge carriers. Carlson supposed nonbridged oxygen ions to be a charge carrier of this depleted region [28]. Compensation of charges allows a drift of the "dissociated" layer through the bulk of the glass. As a result, the space charge imple mentation has formed a layer depleted in sodium oxide with a much lower conductivity [29] and important structural rearrangements [26].

Finally, if one can consider a poled sample as a simple two layer system, the implementation of the electric field should be directly linked to the resistivity of each layer. Assuming constant electric fields in each region, we can write

$j=\sigma_{1} E_{1}=\sigma_{2} E_{2} ; \quad E_{1} d+E_{2}(L \quad d)=V$

where $j$ is the spatially constant current density, $\sigma_{1,2}$ the conductivities and $E_{1,2}$ the electric fields of the depleted layer 

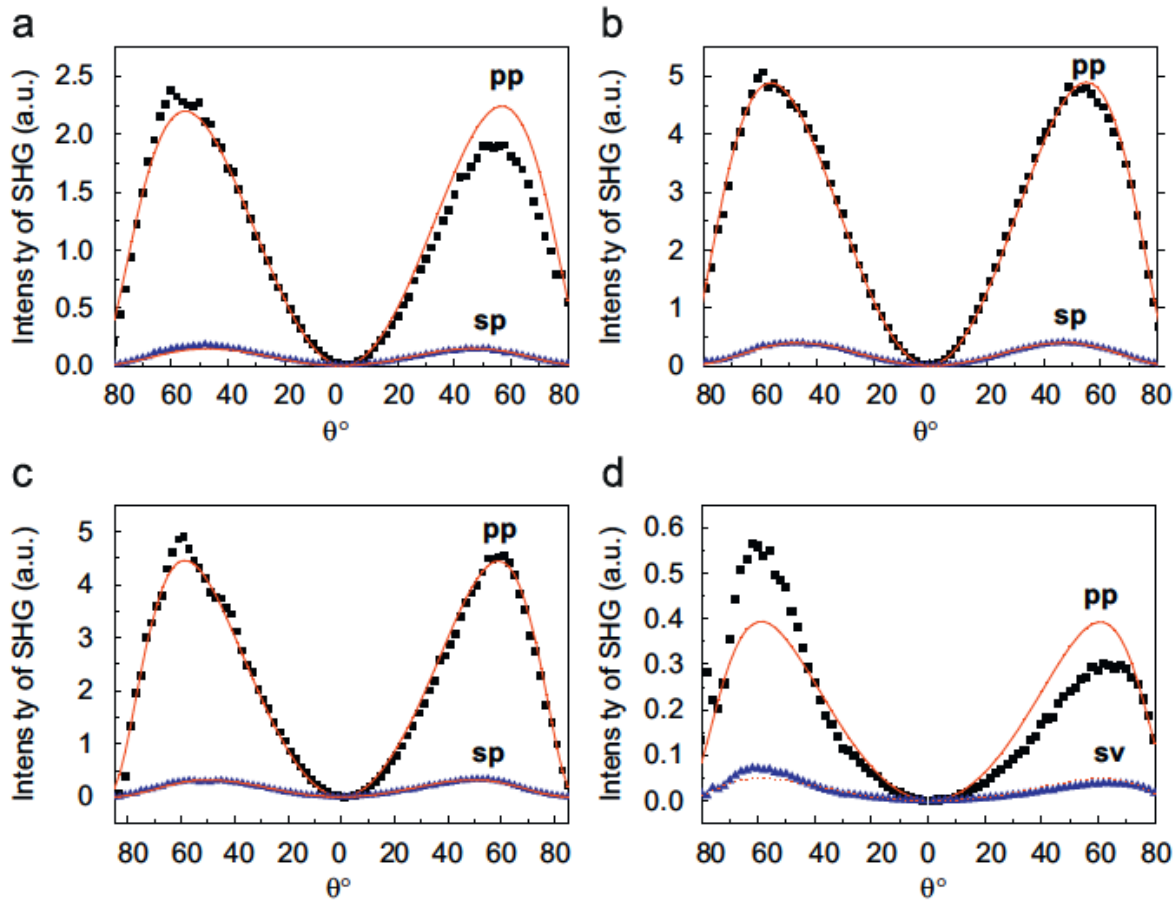

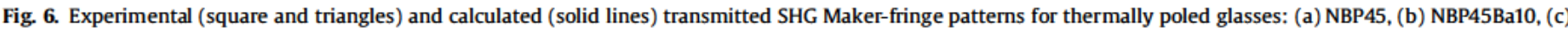
NBP45Ba30, and (d) NBP45Ba50.

a

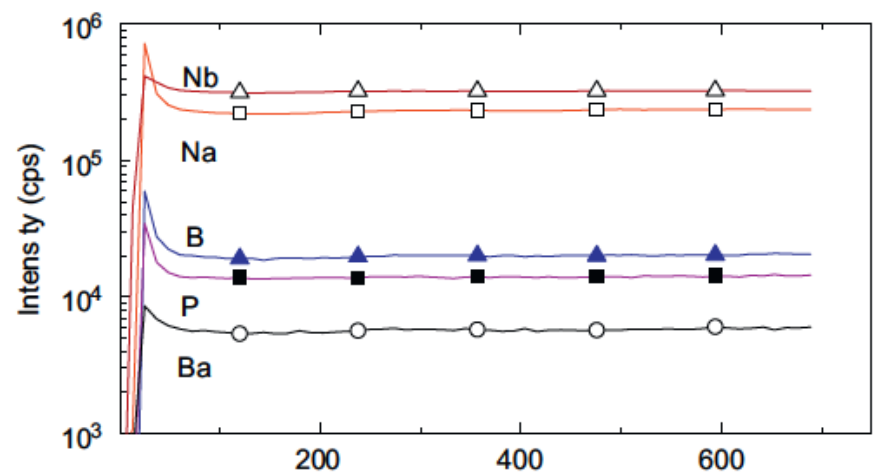

b

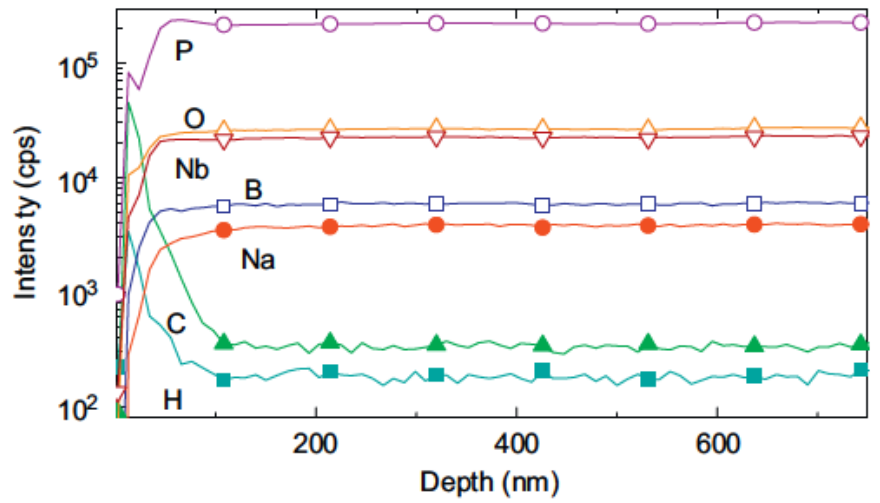

Fig. 7. Profiles of elements distribution obtained by secondary ion mass spectrometry (SIMS) analysis of nonpoled glass NBP45Ba10. Analysis of positively (a) and negatively (b) charged ions are shown.

and the bulk glass, respectively, $L$ the sample thickness and $d$ the thickness of the depleted layer at the anode. We deduce directly the expression of the electric field in the depleted layer as follows:

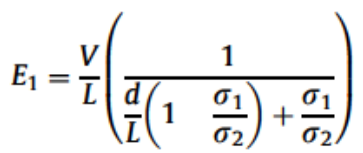

When $\sigma_{1} \ll \sigma_{2}$, and $d \ll L$, the term in parenthesis is much larger than 1 and so the electric field in the depleted layer is much larger than the applied electric field. A strong electric field is thus conditioned by a small conductivity ratio $\sigma_{1} / \sigma_{2}$.

Here, for the poled glass without barium (sample NBP45), dielectric measurements have permitted to quantify the ratio $\sigma_{1} / \sigma_{2}=10^{3}$ [29]. Using Eq. (4) with $d=4 \mu \mathrm{m}, L=700 \mu \mathrm{m}$ and $V=1.5 \mathrm{kV}$, we can estimate $E_{1}=3 \times 10^{8} \mathrm{~V} / \mathrm{m}$, which correspond nicely to values deduced from Eq. (1) [26]. The sodium to barium substitution induces a decrease of the bulk conductivity (i.e. $\sigma_{2}$ ) greater than four orders of magnitude between NBP45 and NBP45Ba80 glasses at the poling temperature. Thus, within this compositional range, we can also expect variations of the conductivity ratio $\sigma_{1} / \sigma_{2}$ which could modify the implementa tion of the internal field at the anode. Additional works are in progress to confirm our conclusions. Hence, regarding the second order optical susceptibility efficiency in poled glasses, these results do spot the probable importance of dielectric properties: (i) before poling with the initial bulk conductivity (equivalent to $\sigma_{2}$ ) and (ii) after poling with the importance of a sufficient contrast of conductivity between the depleted layer and the bulk (optimization of the ratio $\sigma_{1} / \sigma_{2}$ ). The choice of the glass composition seems to be the key point to access to a real optimization of both the space charge implementation and the $\chi^{(2)}$ efficiency.

\section{Conclusion}

Glasses with various concentrations of sodium and barium were investigated in order to estimate the influence of ionic conductivity 

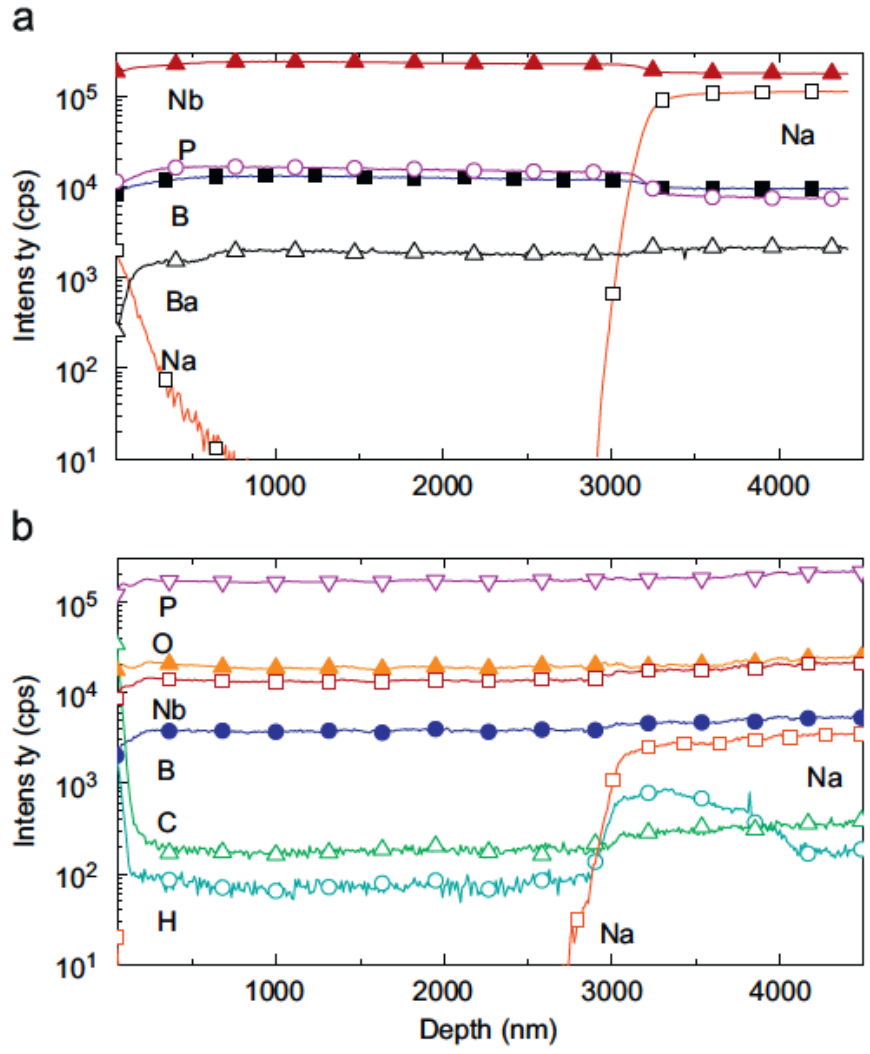

Fig. 8. Profiles of elements distribution obtained by secondary ion mass spectrometry (SIMS) analysis in the anode zone of thermally poled glass NBP45Ba10. Analysis of positively (a) and negatively (b) charged ions are shown.

on the second order optical efficiency of thermally poled glasses. Influence of cation substitution on structural environment, optical and dielectric properties of the glasses was characterized by Raman spectroscopy, crystallization studies, optical measurements and impedance spectroscopy. SIMS measurement has informed on the charge balanced and compensation mechanisms occurring within the NLO layer during the space charge formation. Finally, a tentative to correlate nonlinear optical properties with dielectric character istics is proposed on the basis of a simple electrical model.

\section{Acknowledgments}

A.M. is indebt to INTAS and RFBR no. $070300573 a$ for financial support.
The EU, the Région Aquitaine and the Agence National de la Recherche (ANR) are gratefully acknowledged for financial support through the projects Marie Curie Actions NANONLO (MTKD CT 2006 042301), AMA (Advanced Materials in Aquitaine) Lasinof and ANR 05 BLAN 021201 Reglis.

\section{References}

[1] R.A. Myers, N. Mukherjee, S.R.J. Brueck, Opt. Lett. 16 (1991) 1732.

[2] N. Mukherjee, R.A. Myers, S.R.J. Brueck, J. Opt. Soc. Am. B 11 (1994) 665.

[3] P.G. Kazansky, P.St.J. Russell, Opt. Commun. 101 (1994) 611.

[4] E. Fargin, A. Berthereau, T. Cardinal, G. Le Flem, L Ducasse, L Canioni, P. Segonds, L. Sarger, A. Ducasse, J. Non-Cryst. Solids 203 (1996) 96.

[5] T. Cardinal, E. Fargin, G. Le Flem, M. Couzi, L Canioni, P. Segonds, L. Sarger, A. Ducasse, F. Adamietz, Eur. J. Solid State Inorg. Chem. 33 (1996) 597.

[6] T. Cardinal, E. Fargin, G. Le Flem, S. Leboiteux, J. Non-Cryst. Solids 222 (1997) 228.

[7] B. Jeansannetas, S. Blanchandin, P. Thomas, P. Marchet, J.C. ChamparnaudMsjard, V. Nazabal, E. Fargin, G. Le Flem, M.O. Martin, B. Bousquet, L Canioni, S. Le Boiteux, P. Segonds, L. Sarger, J. Solid State Chem. 146 (1999) 329.

[8] F.C. Garcia, I.C.S. Carvalho, E. Hering. W. Margulis, B. Leshe, Appl. Phys. Lett. 72 (1998) 3252.

[9] H. An, S. Flemming, Appl. Phys. Lett. 89 (2006) 181111; H. An, S. Flemming, J. Opt. Soc. Am. B 23 (2006) 11.

[10] M. Dussauze, E. Fargin, M. Lahaye, V. Rodriguez, F. Adamietz, Opt. Express 13 (2005) 4064

[11] M. Dussauze, A. Malakho, E. Fargin, V. Rodriguez, F. Adamietz, Opt. Mat. 28 (2006) 1417.

[12] V. Nazabal, E. Fargin, C. Labrugere, G. Le Flem, J. Non-Cryst. Solids 270 (2000) 223.

[13] B. Ferreira, E. Fargin, J.P. Manaud, G. Le Flem, V. Rodriguez, T. Buffeteau, J. NonCryst. Solids 343 (2004) 121.

[14] V. Rodriguez, C. Sourisseau, J. Opt. Soc. Am. B 19 (2002) 2650; V. Rodriguez, J. Chem. Phys. 128 (2008) 064707.

[15] M.G. Kuzyk, C.W. Dirk, Characterization Techniques and Tabulations for Organic Nonlinear Optical Materials, Marcel Dekker Inc, New York, 1998.

[16] A.A. Lipovskii, D.K. Tagantsev, B.V. Tatarintsev, A.A. Vetrov, J. Non-Cryst. Solids 318 (2003) 268.

[17] S.W. Martin, Eur. J. Solid State Inorg. Chem. 28 (1991) 163.

[18] L.L. Velli, C.P. Varsamis, E.I. Kamitsos, M. Moenke, D. Ehrt, Phys. Chem. Glasses 46 (2005) 178.

[19] A. Malakho, M. Dussauze, E. Fargin, B.I. Lazoryak, V. Rodriguez, F. Adamietz, J. Solid State Chem. 178 (2005) 1888.

[20] G. Constentin, M.M. Borel, A. Grandin, A. Leclaire, B. Raveau, Mater. Res. Bull. 26 (1991) 1051.

[21] J.C. Dyre, T.B. Schroder, Rev. Mod. Phys. 72 (2000) 873.

[22] S. Ettori, J.C. Peraud, J. Barton, De-ionisation of glass by corona discharge, European Union Patent EP0237431, 1987.

[23] T.G. Alley, S.R.J. Brueck, M. Wiedenbeck, J. Appl. Phys. 86 (1999) 6634.

[24] T.G. Alley, S.R.J. Brueck, A.M. Richard, J. Non-Cryst. Solids 242 (1998) 165.

[25] A. Royon, L. Canioni, B. Bousquet, V. Rodriguez, M. Couzi, C. Rivero, T. Cardinal, E. Fargin, M. Richardson, K. Richardson, Phys. Rev. B 75 (2007) 104207.

[26] M. Dussauze, E.I. Kamitsos, E. Fargin, V. Rodriguez, J. Phys. Chem. C 111 (2007) 14560.

[27] A.J. Kontkiewicz, A.M. Kontkiewicz, J. Siejka, S. Sen, G. Nowak, Appl. Phys. Lett. 65 (1994) 1436.

[28] D.E. Carlson, J. Am. Ceram. Soc. 57 (1974) 291.

[29] M. Dussauze, O. Bidault, E. Fargin, M. Maglione, V. Rodriguez, J. Appl. Phys. 100 (2006) 034905. 